\section{Electrocatalytic Reduction of}

\section{Oxygen: Gold and Gold-Platinum}

Nanoparticle

Catalysts Prepared by Two-Phase Protocol

\author{
Mathew M. Maye, Nancy N. Kariuki, Jin \\ Luo, Li Han, Peter Njoki, Lingyan Wang, \\ Yan Lin, H. Richard Naslund ${ }^{1}$, Chuan-Jian \\ Zhong*
}

Department of Chemistry, State University of New York at Binghamton, Binghamton, New York 13902, USA (*cjzhong@binghamton.edu)

1 Department of Geological Sciences, State University of New York at Binghamton, Binghamton, New York 13902, USA

\begin{abstract}
This paper describes recent results of an investigation of gold $(\mathrm{Au})$ and gold-platinum (AuPt) nanoparticle electrocatalysts for fuel cell reaction at the cathode, i.e., oxygen reduction reaction (ORR). The Au nanoparticles and AuPt nanoparticles with different bimetallic ratios were prepared by a two-phase protocol and supported on carbon black materials. The catalysts were thermally activated under controlled calcination temperatures. The electrocatalytic ORR activities were characterized using voltammetric and rotating disk electrode techniques. We have also attempted an initial comparison of the electrocatalytic activities of our $\mathrm{Au} / \mathrm{C}$ and AuPt/C catalysts with commercially-available Pt/C and PtRu/C catalysts (E-tek) under the same voltammetric measurement conditions. The results revealed important insights into the electrocatalytic activity of our catalysts, and have important implications to the design of highly active fuel cell catalysts.
\end{abstract}

\section{Introduction}

The high conversion efficiencies and low pollution of hydrogen and direct methanol fuel cells are becoming increasingly attractive power sources for mobile and stationary applications such as on-board electric power sources for advanced propulsion systems and generation of non-polluting vehicles. While researchers around the world are developing potential fuel cell applications including electric vehicles and portable powers, the development faces challenging scientific problems in the areas of materials science, interfacial science and catalysis. In proton exchange membrane fuel cells (PEMFCs) hydrogen ions must be transported through a Nafion membrane, hydrocarbon fuels must be converted to pure hydrogen by reforming, and the overall conversion requires a complex process technology and substantial investments in safety and controls. Direct methanol fuel cells (DMFCs) offer a simpler solution and require no reformer. Currently, the energy density ( 2000 $\mathrm{Wh} / \mathrm{kg}$ ) and operating cell voltage (0.4 V) for methanol fuel cells are much lower than the theoretical energy density ( $6000 \mathrm{Wh} / \mathrm{kg}$ ) and the thermodynamic potential ( 1.2 V) due to poor activity of the anode catalysts and "methanol cross-over" to the cathode electrode $(1,2)$, which lead to a loss of about one-third of the available energy at the cathode and another one-third at the anode. Pt-group metals are extensively studied for both anode and cathode catalysts, but a major problem is the poisoning of Pt by CO-like intermediate species (3-5). On the cathode, the kinetic limitation of the oxygen reduction reaction (ORR) is a problem of interest in proton exchange membrane fuel cells operating at low temperature $\left(<100^{\circ} \mathrm{C}\right)$ and in DMFCs $(2,6)$. The rate of breaking $\mathrm{O}=\mathrm{O}$ bond to form water strongly depends on the degree of its interaction with the adsorption sites of the catalyst, and competition with other species in the electrolyte (e.g., $\mathrm{CH}_{3} \mathrm{OH}$ ). One problem in using Pt as catalyst is the strong adsorption of $\mathrm{OH}$ forming $\mathrm{Pt}-\mathrm{OH}$, which causes inhibition of the $\mathrm{O}_{2}$ reduction.

The exploration of gold nanoparticles in catalysis has attracted a wide range of fundamental and industrial interests (7-17). Recent advances have shown potential applications of gold-based nanoparticle catalysts in fuel cell related catalytic reactions $(18,19)$. We have recently investigated gold and alloy nanoparticles in electrocatalysis of fuel cell reactions, including $\mathrm{CO}$ and methanol oxidation (20-27) and $\mathrm{O}_{2}$ reduction reactions (25-27). Based on recent insights into the surface properties for the adsorption of oxygen and the catalytic properties of gold at nanoscale sizes (18,28-31), we envision that the bimetallic AuPt composition may produce a synergistic catalytic effect that involves the suppression of adsorbed poisonous species and the change in electronic band structure to modify the strength of the 


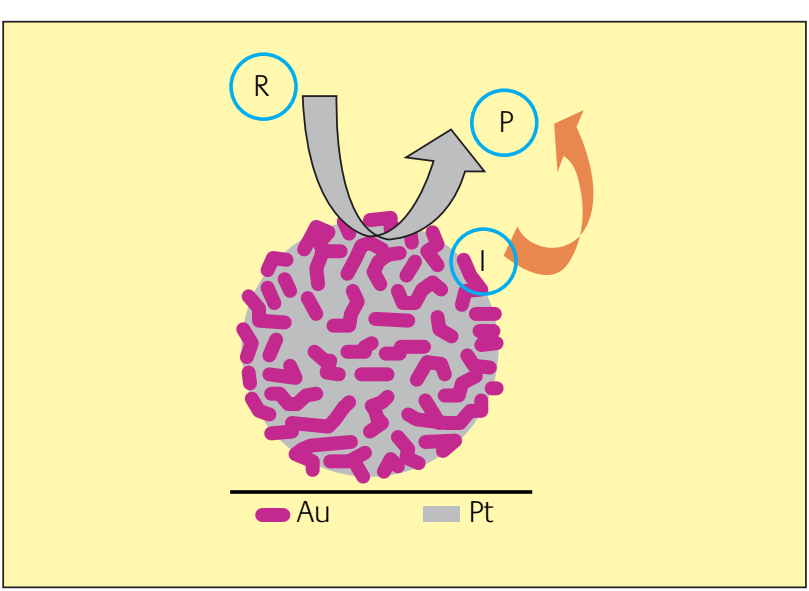

\section{Scheme 1}

Schematic illustration of AuPt nanoparticle and the catalytic reactions involving adsorption, interfacial reaction, and desorption of reactant $(R)$, intermediate (I) and product (P)

surface adsorption for ORR (Scheme 1). Bimetallic AuPt is a known electrocatalyst for oxygen reduction in alkaline fuel cells. There have been however few reports for the study of AuPt nanoparticles with controllable size and composition in fuel cell catalyst applications (19). Such a study is important because the metal nanoparticles (1-10 nm) undergo a transition from atomic to metallic properties, and the bimetallic composition could produce the synergistic effect. One of the earlier insights about AuPt bulk alloy catalyst is the important role of $\mathrm{OH}_{\text {ads }}^{-}$in alkaline medium under which the presence of $\mathrm{Au}$ could reduce the strength of the $\mathrm{Pt}-\mathrm{OH}$ formation. How this property operates at the nanoscale gold and gold-platinum surface is unknown.

In this paper, we report the results of our preliminary investigation of the electrocatalytic ORR activities of carbonloaded Au and AuPt nanoparticle catalysts. Unlike some of our earlier electrocatalytic studies in which gold nanoparticles were assembled on planar glassy carbon electrodes (20-24), the gold and gold-platinum nanoparticles with different bimetallic ratios prepared by two-phase protocol (32-35) are assembled on carbon black support materials and activated by calcination. More importantly, we have attempted an initial comparison of the electrocatalytic ORR activities of our carbon-supported Au and AuPt nanoparticle catalysts with commercially-available Pt/C and PtRu/C catalysts (E-tek) under the same voltammetric measurement conditions. It is important to note that our approach to the preparation of catalysts can lead to a better control over size, shape, composition or surface properties $(32,36)$ in comparison with traditional approaches such as co-precipitation, depositionprecipitation, ion-exchange, impregnation, and successive reduction and calcination $(3,4,15)$.

\section{Experimental}

Chemicals. Decanethiol (DT, 96\%), hydrogen tetrachloroaurate $\left(\mathrm{HAuCl}_{4}, 99 \%\right)$, tetraoctylammonium bromide (TOABr, 99\%), hydrogen hexachloroplatinate (IV) $\left(\mathrm{H}_{2} \mathrm{PtCl}_{6}\right.$, 99.995\%), and $\mathrm{NaBH}_{4}$ were purchased from Aldrich and used as received. Other chemicals included hexane (99.9\%) and toluene (99.8\%) from Fisher, and methanol (99.9\%) and ethanol (99.9\%) from Aldrich. Water was purified with a Millipore Milli-Q water system. Catalysts such as 20\% Pt on Vulcan XC-72 (Pt/C) and 20\% PtRu on Vulcan XC-72 (PtRu/C) were purchased from E-Tek.

Catalyst Preparation. Gold nanoparticles of 2-nm core size encapsulated with an alkanethiolate monolayer shell (Au) were synthesized by the standard two-phase method (32). Gold-platinum nanoparticles of 2-nm core size encapsulated with an alkanethiolate monolayer shell (AuPt) were synthesized by a modified two-phase method (35). Briefly $\mathrm{AuCl}_{4}{ }^{-}$and $\mathrm{PtCl}_{6}{ }^{2-}$ were first transferred from aqueous solution of $\mathrm{HAuCl}_{4}$ and $\mathrm{H}_{2} \mathrm{PtCl}_{6}$ into toluene solution using a phase transfer reagent (tetraoctylammonium bromide). Thiols (e.g., decanethiol, DT) were added to the organic solution at a 4:1 mole ratio (DT/AuPt), and an excess of aqueous $\mathrm{NaBH}_{4}$ was slowly added for the reduction reaction. The $\mathrm{Au}_{81} \mathrm{Pt}_{19}$ and $\mathrm{Au}_{68} \mathrm{Pt}_{32}$ nanoparticles reported in this paper were obtained by controlling the relative feed ratio of $\mathrm{HAuCl}_{4}$ and $\mathrm{H}_{2} \mathrm{PtCl}_{6}$ in synthesis and the post-synthesis cleaning procedure, details of which will be reported in another paper.

The composition was analyzed using the DCP method, which was performed using an ARL Fisons SS-7 Direct Current Plasma - Atomic Emission Spectrometer (DCP-AES). Measurements were made on emission peaks at $267.59 \mathrm{~nm}$ and $265.95 \mathrm{~nm}$, for $\mathrm{Au}$ and Pt, respectively. The nanoparticle samples were dissolved in concentrated aqua regia, and then diluted to concentrations in the range of 1 to 50 ppm for analysis. Calibration curves were made from dissolved standards with concentrations from 0 to 50 ppm in the same acid matrix as the unknowns. Detection limits, based on three standard deviations of the background intensity, are $0.008 \mathrm{ppm}$ and $0.02 \mathrm{ppm}$ for Au and Pt. Standards and unknowns were analyzed 10 times each for 3 second counts. Instrument reproducibility, for concentrations greater than 100 times the detection limit, results in $< \pm 2 \%$ error.

Carbon black XR-72C was used as support for the nanoparticles. A controlled amount of Au or AuPt nanoparticles was added into the suspension of carbon black, which was sonicated and followed by stirring overnight. The loading of Au or AuPt on carbon support was controlled by the weight ratio of Au or AuPt nanoparticles vs. carbon black. The actual loading of metals was determined by TCA and DCP analysis. 
The carbon-loaded nanoparticle catalysts were treated in a tube-furnace by heating at $300^{\circ} \mathrm{C}$ under $20 \% \mathrm{O}_{2} / \mathrm{N}_{2}$ for 1 hour and calcination at $400^{\circ} \mathrm{C}$ under $15 \% \mathrm{H}_{2} / \mathrm{N}_{2}$ for 2 hours. The carbon-loaded Au or AuPt nanoparticles are denoted as Au/C or AuPt/C.

Electrode Preparation. Glassy carbon (CC) disks (geometric area: $0.07 \mathrm{~cm}^{2}$ for cyclic voltammetric measurement and $0.20 \mathrm{~cm}^{2}$ for rotating disk electrode measurement) were polished with $0.03 \mu \mathrm{m} \mathrm{Al} \mathrm{O}_{3}$ powders. The geometric area of the substrate electrode (glassy carbon), not the surface area of the catalyst itself, provides a measure of the loading of catalyst on the electrode surface used for the voltammetric characterization. A typical suspension of the catalysts was prepared by suspending $1 \mathrm{mg}$ catalysts (Au/C, AuPt/C, Pt/C, PtRu/C) in $1 \mathrm{~mL}$ solution of $5 \%$ Nafion, and sonicated for 15 mins. The suspension was stable for days. The suspension was then quantitatively transferred to the surface of the polished GC disk. The electrodes were dried overnight at room temperature.

TEM micrographs for both $\mathrm{Au}$ and Au-Pt nanoparticles have shown $\sim 2 \mathrm{~nm}$ core size on carbon black (30-50 nm spheres) support, and well-dispersed spatial property. The particle sizes were about 3-5 nm diameters after thermal treatment. A detailed spectroscopic and microscopic characterization of the composition, size and crystallinity of the catalysts will be reported elsewhere.

Measurements. The cyclic voltammetry and rotating disk electrode measurements were performed at room temperature. All experiments were performed in threeelectrode electrochemical cells. All electrolytic solutions were de-aerated with high purity argon or nitrogen before the measurement. All potentials are given with respect to the reference electrode of $\mathrm{Ag} / \mathrm{AgCl}$ saturated $\mathrm{KCl}$, which is +0.20 $\checkmark$ with respect to NHE reference. The cyclic voltammetric measurements were performed by using a microcomputer- controlled potentiostat (Model 273, PARC). The rotating disk electrode (RDE) measurements were performed using a rotating disk electrode measurement system (Model AFCBP1, Pine Instrument).

\section{Results and Discussion}

\section{Au/C}

Figure 1 shows a typical set of cyclic voltammetric (CV) curves for ORR at Au/C catalyst (17\% wt metal) in $0.5 \mathrm{M} \mathrm{KOH}$ and 0.5 $\mathrm{M} \mathrm{H}_{2} \mathrm{SO}_{4}$ electrolytes saturated with $\mathrm{O}_{2}$. The $\mathrm{CV}$ curves in the absence of oxygen are included as a blank for comparison. The blanks reveal an oxidation-reduction wave of gold oxide at $\sim+200 \mathrm{mV}$ in the alkaline electrolyte but little redox current in the acidic electrolyte. In contrast, the appearance of the cathodic wave is observed at $-150 \mathrm{mV}$ in the alkaline electrolyte and at $+50 \mathrm{mV}$ in the acidic electrolyte. This finding indicates that the $\mathrm{Au}$ catalyst is active towards $\mathrm{O}_{2}$ reduction in both electrolytes.

Figure 2 shows two representative sets of RDE data for further assessing the ORR activities in the above two systems. From Levich plots (37) of the limiting current vs. rotating speed ( $B \& C$ ), one can derive the electron transfer number (n). We obtained $n=3.1$ for ORR in $0.5 \mathrm{M} \mathrm{KOH}$ electrolyte, and 2.9 for ORR in $0.5 \mathrm{M} \mathrm{H}_{2} \mathrm{SO}_{4}$ electrolyte. The error bar was \pm 0.2 . The intermittent n-value between 2 and 4 indicates that the electrocatalytic ORR at the Au/C catalyst likely involved mixed $2 \mathrm{e}^{-}$and $4 \mathrm{e}^{-}$reduction processes.

\section{AuPt/C}

Figure 3 shows a typical set of CV curves obtained at $\mathrm{Au}_{81} \mathrm{Pt}_{19} / \mathrm{C}$ catalyst (24\% wt metals) in both alkaline and acidic electrolytes. There are two important pieces of evidence supporting the presence of both Au and Pt on the surface of the nanoparticle catalyst. First, similar to the CV curve for the

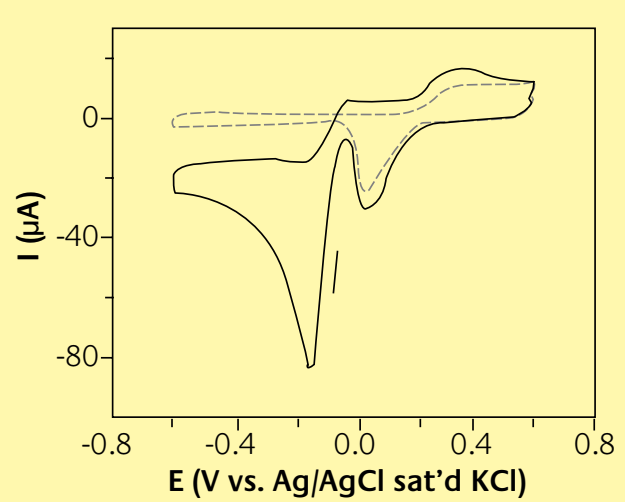

(A)

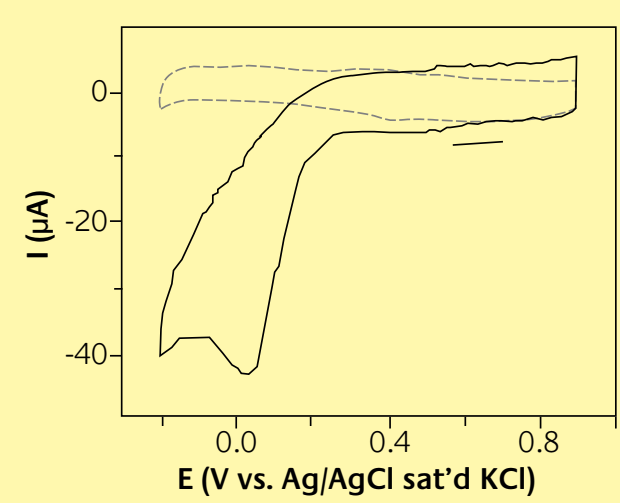

(B)

\section{Figure 1}

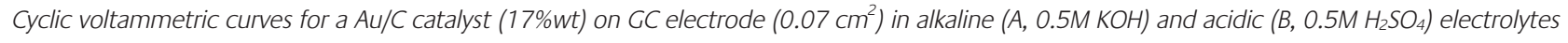
saturated with $\mathrm{O}_{2}$ (solid curves) and $\mathrm{Ar}$ (dash curves). Scan rate: $50 \mathrm{mV} / \mathrm{s}$ 


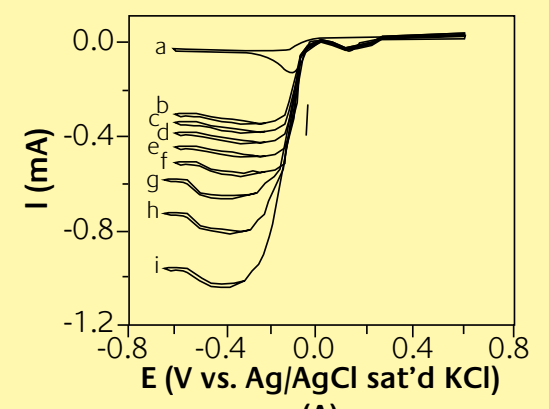

(A)

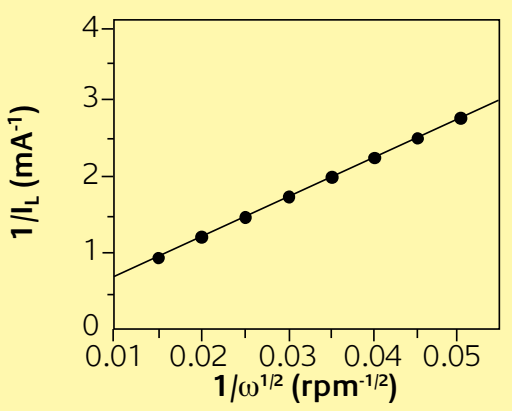

(B)

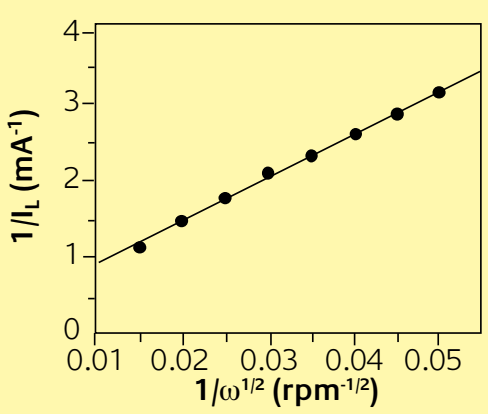

(C)

\section{Figure 2}

RDE curves for a Au/C catalyst (17\%wt) on GC electrode $\left(0.2 \mathrm{~cm}^{2}\right)$ in the alkaline (A, O.5M KOH) electrolyte saturated with $\mathrm{O}_{2}$. (Rpm: (a) 0; (b) 400; (c) 500; (d) 630 (e) 820; (f) 1110; (g) 1600; (h) 2500; (i) 4500. Scan rate: 20 mV/s), and Levich plots of the limiting currents in the alkaline (B, O.5M KOH) and acidic $\left(\mathrm{C}, 0.5 \mathrm{M} \mathrm{H}_{2} \mathrm{SO}_{4}\right)$ electrolytes with saturated $\mathrm{O}^{2}$

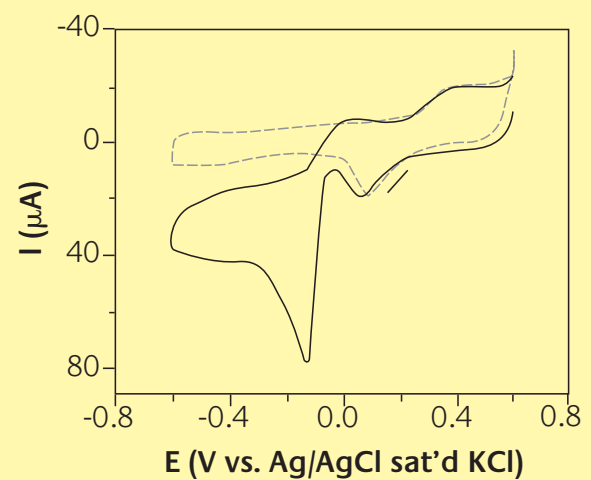

(A)

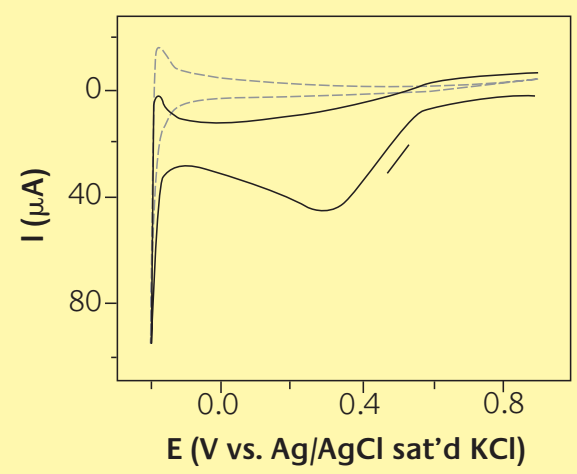

(B)

Figure 3

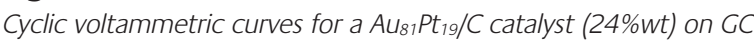
electrode $\left(0.07 \mathrm{~cm}^{2}\right)$ in alkaline $(A, 0.5 \mathrm{M} \mathrm{KOH})$ and acidic $(B, 0.5 \mathrm{M}$ $\mathrm{H}_{2} \mathrm{SO}_{4}$ ) electrolytes saturated with $\mathrm{O}_{2}$ (solid curves) and $\mathrm{Ar}$ (dash curves). Scan rate: $50 \mathrm{mV} / \mathrm{s}$

$\mathrm{Au} / \mathrm{C}$ catalyst in the absence of oxygen (Figure $1 \mathrm{~A}$ dashed line), the observation of the oxidation-reduction wave of gold oxide at $\sim 200 \mathrm{mV}$ at the $\mathrm{Au}_{81} \mathrm{Pt}_{19} / \mathrm{C}$ catalyst in the $\mathrm{O}_{2}$-free alkaline electrolyte (Figure 3A dashed line) is a clear indication of the presence of Au on the catalyst. Second, the observation of the hydrogen reduction-oxidation currents at $-200 \mathrm{mV}$ in the $\mathrm{O}_{2}$-free acidic electrolyte, which is characteristic of hydrogen adsorption and reduction at Pt electrodes (see a later sub-section), is strong evidence for the presence of Pt on the catalyst surface.

In comparison with the data for $\mathrm{Au} / \mathrm{C}$ catalysts, there are two important observations for the electrocatalytic activity of the AuPt nanoparticle catalysts. First, the ORR wave at the $\mathrm{Au}_{81} \mathrm{Pt}_{19} / \mathrm{C}$ catalyst is observed at about the same potential $(-150 \mathrm{mV})$ as that for the $\mathrm{Au} / \mathrm{C}$ in the alkaline electrolyte. We also note that a very small wave is detectable at $-450 \mathrm{mV}$ for the AuPt/C catalyst. Second, the ORR waves are highly dependent on the nature of the electrolyte. This wave for $\mathrm{Au}_{81} \mathrm{Pt}_{19} / \mathrm{C}$ is observed at $\sim+300 \mathrm{mV}$ in the acidic electrolyte, which is much more positive than that for the $\mathrm{Au} / \mathrm{C}(+25 \mathrm{mV}$ ) in the same electrolyte. In this case, the ORR currents detected at below $+25 \mathrm{mV}$ are characteristic of hydrogen adsorption-reduction at Pt electrodes. The result thus suggests that there is a significant fraction of Au on the bimetallic catalyst which keeps the nanoscale gold property unchanged in basic condition, but modifies the catalytic property of Pt in the acidic electrolyte.

The dependence of the electrocatalytic activity on the relative bimetallic composition of the catalyst was further examined. Figure 4 shows a typical set of CV curves obtained at $\mathrm{Au}_{68} \mathrm{Pt}_{32} / \mathrm{C}$ catalyst (39\%wt metals). We note that the metal loading is somewhat higher than that in the previous case ( 20\%wt metals).

Two important changes are evident. First, while the ORR peak potential at $-190 \mathrm{mV}$ remains largely unchanged, a significant wave component of the ORR is evident at $-400 \mathrm{mV}$ in the alkaline electrolyte, which showed an increase for the $\mathrm{Au}_{68} \mathrm{Pt}_{32} / \mathrm{C}$ in comparison with that for the previous $\mathrm{Au}_{81} \mathrm{Pt}_{19} / \mathrm{C}$. Second, the ORR wave for the $\mathrm{Au}_{68} \mathrm{Pt}_{32} / \mathrm{C}$ showed a shift of the peak potential to a much more positive 


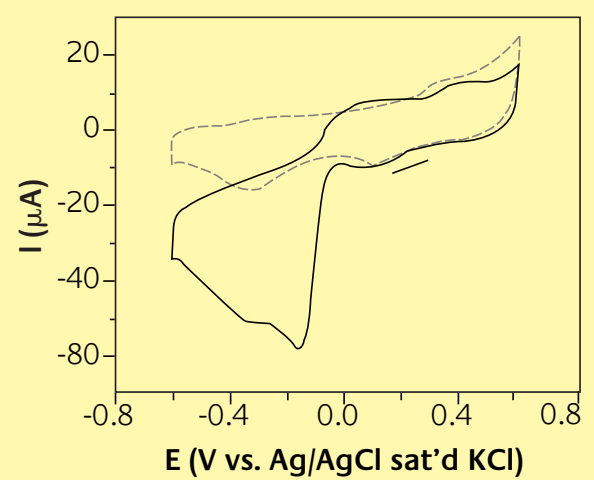

(A)

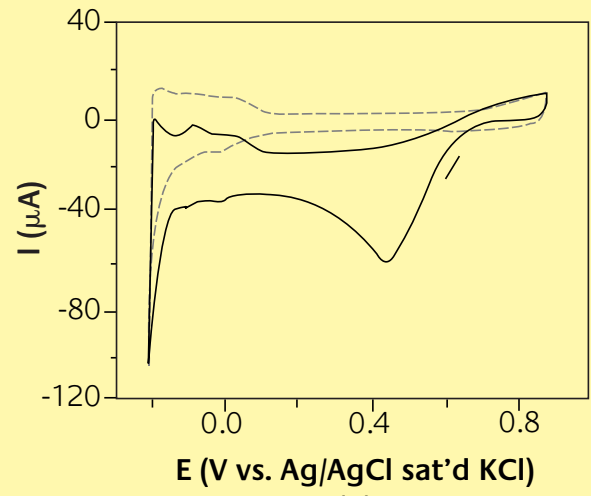

(B)

\section{Figure 4}

Cyclic voltammetric curves for a $\mathrm{Au}_{68} \mathrm{Pt} \mathrm{t}_{32} / \mathrm{C}$ catalyst (39\%wt) on GC electrode $\left(0.07 \mathrm{~cm}^{2}\right)$ in alkaline $(A, 0.5 \mathrm{M} \mathrm{KOH})$ and acidic $(B, 0.5 \mathrm{M}$ $\mathrm{H}_{2} \mathrm{SO}_{4}$ ) electrolytes saturated with $\mathrm{O}_{2}$ (solid curves) and $\mathrm{Ar}$ (dash curves). Scan rate: $50 \mathrm{mV} / \mathrm{s}$

potential $(\sim+500 \mathrm{mV})$ than that for the $\mathrm{Au}_{81} \mathrm{Pt}_{19} / \mathrm{C}$ in the acidic electrolyte. Both findings suggest that the electrocatalytic activity of Au and Pt metal components in the nanoparticle catalysts is dependent on the nature of the electrolyte. It appears that the catalysis at the individual $\mathrm{Au}$ or Pt surface site is operative in the alkaline electrolyte, whereas the catalysis of the bimetallic surface sites is operative in the acidic electrolyte.

To further evaluate the electrocatalytic properties, rotating disk electrode (RDE) experiments were performed to characterize the number of electrons transferred in the electrocatalytic ORR process. Figure 5 shows a typical set of RDE data obtained for ORR at $\mathrm{Au}_{81} \mathrm{Pt}_{19} / \mathrm{C}$ catalyst (24\% metal loading) in both alkaline and acidic electrolytes.

From Levich plots (inserts), one derives the value for the electron transfer number (n). We found that $\mathrm{n}=3.6$ in $0.5 \mathrm{M}$ $\mathrm{KOH}$ and 3.4 in $0.5 \mathrm{M} \mathrm{H}_{2} \mathrm{SO}_{4}(\sim \pm 0.4$ error bar) for ORR at the $\mathrm{Au}_{81} \mathrm{Pt}_{19} / \mathrm{C}$ catalyst. There is a noticeable increase in the $\mathrm{n}$ value for the bimetallic AuPt/C catalyst in comparison with that for the monometallic $\mathrm{Au} / \mathrm{C}$ catalyst.

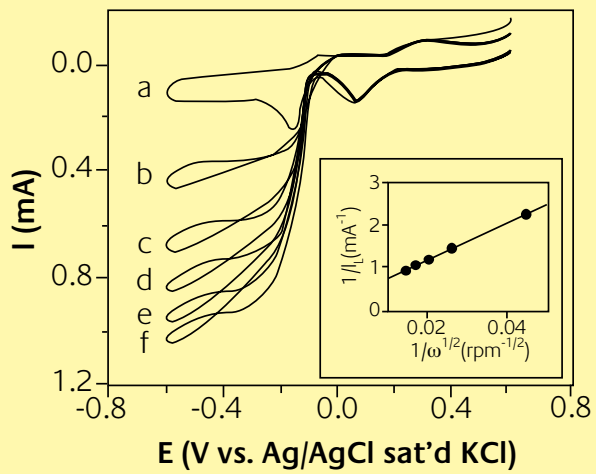

(A)

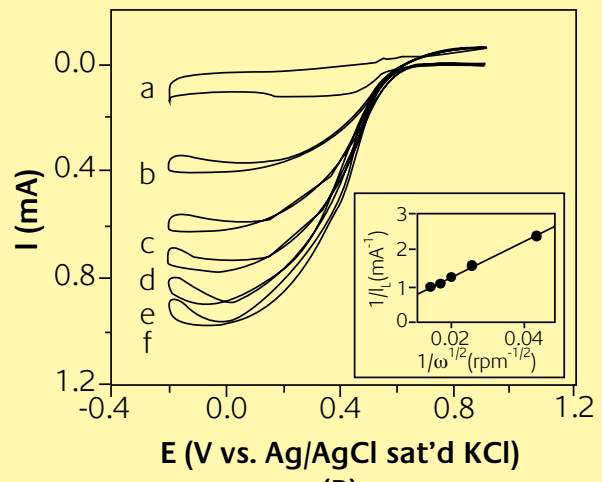

(B)

\section{Figure 5}

RDE Curves for a $A u_{81} P t_{19} / C$ catalyst (24\%wt) on CC electrode $\left(0.2 \mathrm{~cm}^{2}\right)$ in alkaline $(\mathrm{A}, \mathrm{O} .5 \mathrm{M} \mathrm{KOH})$ and acidic $\left(\mathrm{B}, 0.5 \mathrm{M} \mathrm{H}_{2} \mathrm{SO}_{4}\right)$ electrolytes saturated with $\mathrm{O}_{2}$. (Rpm: (a) O; (b) 500; (c) 1500; (d) 2500; (e) 3500; (f) 4500. Scan rate: $10 \mathrm{mV} / \mathrm{s})$. Levich plots of the limiting current are included as inserts

\section{Comparison of Electrocatalytic activities}

We compare now the above electrochemical data for our Au/C (20\% metals) and AuPt/C catalysts (20\% metals) with those from commercially-available catalysts, namely E-tek's Pt/C (20\% metals) and PtRu/C catalysts (20\% metals).

Figure 6 shows a set of electrocatalytic ORR data obtained at E-tek's Pt/C catalysts (20\% metals) in both alkaline and acidic electrolytes. In the alkaline electrolyte, the reduction wave at Pt/C is small at $-190 \mathrm{mV}$, but predominant at -400 $\mathrm{mV}$. In the acidic electrolyte, the reduction wave at $\mathrm{Pt} / \mathrm{C}$ is at +550 mV, about 100-200 mV more positive than the AuPt/C catalyst. The currents detected at below $+50 \mathrm{mV}$ are characteristic of hydrogen adsorption and reduction at Pt electrodes.

For electrocatalytic ORR at E-tek's PtRu/C catalysts (20\% metals), the reduction peak potential at PtRu/C was found to shift negatively by $50-100 \mathrm{mV}$, consistent with the fact that the PtRu/C catalyst is less active than that for $\mathrm{Pt} / \mathrm{C}$ catalyst. To ensure that the quantity of catalysts falls in a linear region, we compared CV data with different catalyst quantities on the 


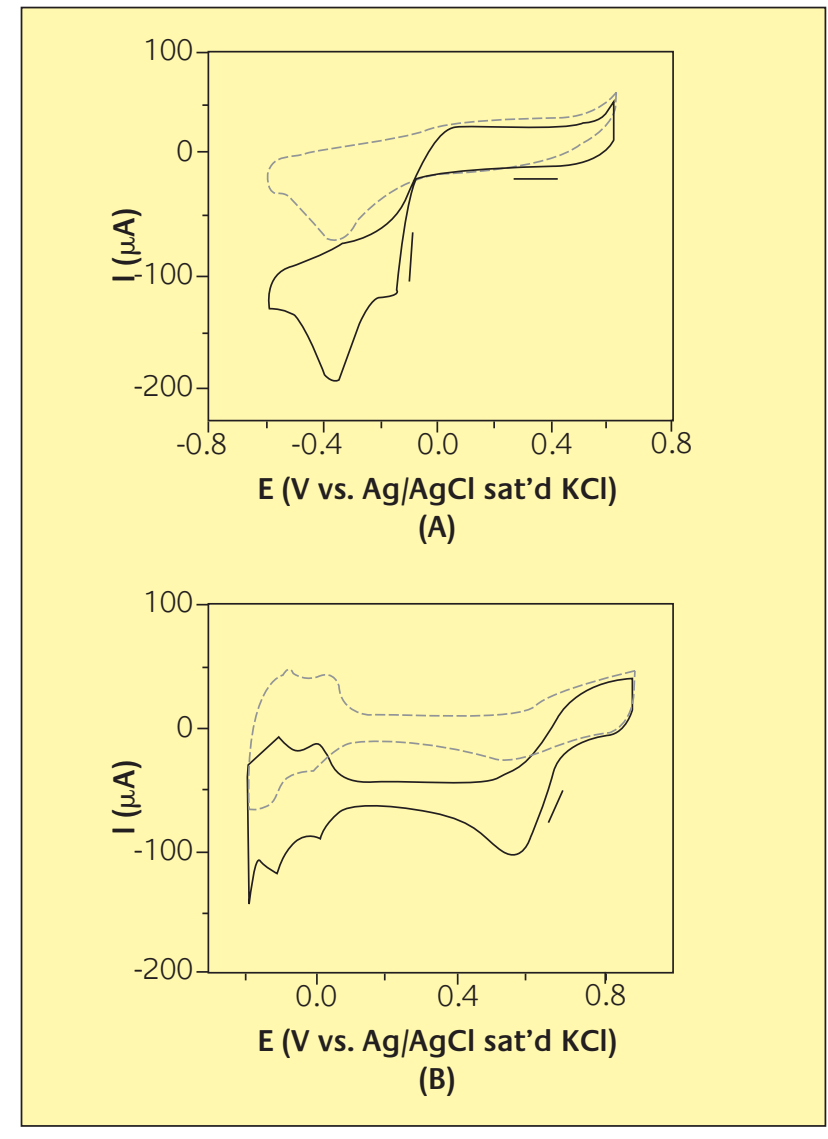

Figure 6

Cyclic voltammetric curves for a E tek's Pt/C catalysts (20\%wt) on CC electrode $\left(0.07 \mathrm{~cm}^{2}\right)$ in $0.5 \mathrm{M} \mathrm{KOH}(\mathrm{A})$ and $0.5 \mathrm{M} \mathrm{H}_{2} \mathrm{SO}_{4}(B)$ in the presence (solid curves) and absence (dash curves) of saturated $\mathrm{O}_{2}$. Scan rate: $50 \mathrm{mV} / \mathrm{s}$

electrode surface. We found that there is a close linearity between peak current and catalyst quantity and the potential shift with different catalyst loading is insignificant. The finding thus ensured the validity of the above catalytic comparison. Similar results have also been observed for the other catalysts tested. Table 1 summarizes several sets of electrocatalytic data to quantitatively compare ORR activities for different catalysts.

The electrocatalysts were evaluated by both potential and current density parameters. In the voltammetric experiment, the potential measured provides information to assess the difference of the reaction potential and the thermodynamic potential, whereas the current reflects the reaction rate. The best catalyst has the lowest overpotential and the highest current density.

The comparison of these electrocatalytic data with different bimetallic compositions and metal loading, while preliminary at this stage, nevertheless provides us important information for an initial assessment of the catalytic activity of the AuPt catalysts. There are two important findings from comparing the peak potentials and peak currents. First, in the alkaline electrolyte, the ORR peak potentials at the $\mathrm{Au} / \mathrm{C}$ and AuPt/C catalysts with $>60$ Au\% are slightly more positive (by 10-40 mV) than that for the Pt/C, and slightly more positive (by $100-120 \mathrm{mV}$ ) than that for the PtRu/C catalysts. This finding suggests that their activities are largely comparable. On the other hand, the peak current density for the AuPt, after being normalized to the total metal loading (which serves as a measure of the turnover number for the catalytic activity), is either comparable or smaller than the E-tek's catalysts by a factor of $\sim 2$. The data are indicative of a better or comparable catalytic activity for the Au/C and AuPt/C catalysts than for the Pt/C or PtRu/C catalysts in the alkaline electrolyte.

Second, significant changes in peak potentials have been observed for AuPt/C catalysts in the acidic electrolyte in comparison with peak potentials observed for Au/C, Pt/C and PtRu/C. Clearly, there is a major positive shift of peak potential upon introducing Pt in the bimetallic catalyst. The peak potential is slightly lower than those for the Pt/C and PtRu/C catalysts (by up to $\sim 300 \mathrm{mV}$ ), depending on the

\section{Table 8}

Comparison of ORR (saturated $\mathrm{O}_{2}$ ) reduction peak potential $\left(E_{p c}\right)$ and current (i $\left.i_{p}\right)$.

\begin{tabular}{|c|c|c|c|c|c|c|}
\hline \multirow[b]{2}{*}{ Catalyst } & \multirow[b]{2}{*}{$\mathbf{W t} \% \mathbf{M t}$} & \multirow[b]{2}{*}{$M_{1}: M_{2}$} & \multicolumn{2}{|c|}{$0.5 \mathrm{M} \mathrm{KOH}$} & \multicolumn{2}{|c|}{$0.5 \mathrm{M} \mathrm{H}_{2} \mathrm{SO}_{4}$} \\
\hline & & & $\mathrm{E}_{\mathrm{pc}}$ & $\mathbf{i}_{\mathrm{pc}}$ & $\mathrm{E}_{\mathrm{pc}}$ & $\mathbf{i}_{\mathrm{pc}}$ \\
\hline & & & $\mathrm{mV}$ & $\left(\mathrm{mA} / \mathrm{cm}^{2} / \mathrm{mg} \mathrm{Mt}\right)$ & $\mathrm{mV}$ & $\left(\mathrm{mA} / \mathrm{cm}^{2} / \mathrm{mg} \mathrm{Mt}\right)$ \\
\hline $\mathrm{Pt} / \mathrm{C}^{(\mathrm{E})}$ & $20 \% \mathrm{Pt}$ & & $-184 \&-383$ & $2125 \& 3464$ & +550 & 1821 \\
\hline $\mathrm{PtRu} / \mathrm{C}^{(\mathrm{E})}$ & $20 \%$ PtRu & $1: 1$ & $-266 \&-433$ & $2357 \& 2116$ & +425 & 1155 \\
\hline $\mathrm{Au} / \mathrm{C}$ & $17 \% A u$ & & -145 & 1744 & +23 & 903 \\
\hline AuPt/C & 24\%AuPt & $81: 19$ & -135 & 1147 & +280 & 677 \\
\hline AuPt/C & $39 \% \mathrm{AuPt}^{\mathrm{a})}$ & $68: 32$ & $-172 \&-323$ & $530 \& 467$ & +454 & 540 \\
\hline
\end{tabular}

Electrode coverage, $57 \mathrm{\mu g}$ (metals/C) / $\mathrm{cm}^{2}$ : E: E tek's catalysts. Electrode area: $0.07 \mathrm{~cm}^{2}$; Scan rate: $50 \mathrm{mV} / \mathrm{s}$; Ref electrode: Ag/AgCl, Sat'd KCl. Note: ${ }^{\text {a) }}$ In the catalysts, there could be a small fraction of salt residuals left from the synthesis. $M_{1}: M_{2}$ is the atomic ratio of Au vs. Pt, for AuPt and Pt vs. Ru for PtRu.; Mt: total metals. 
relative Pt composition in the bimetallic nanoparticle. The peak current is about half of those observed for the Pt/C and PtRu/C catalysts. Therefore, the bimetallic AuPt composition played a significant role in the modification of the electrocatalytic ORR activity.

The Levich plot analysis of the RDE data for the ORR at Etek's Pt/C catalyst ( $20 \% \mathrm{wt}$ ) in acidic electrolyte revealed $\mathrm{n}=$ $4.0 \pm 0.2$, consistent with a $4 \mathrm{e}^{-}$process for the reduction of $\mathrm{O}_{2}$ to $\mathrm{H}_{2} \mathrm{O}$ at the Pt catalyst. Similar results have also been obtained for ORR in the alkaline electrolyte. In comparison with the Pt/C data, the $n$ values obtained with our $\mathrm{Au} / \mathrm{C}$ and AuPt/C catalysts are in between $3.0 \sim 3.6$, displaying an increase of $\mathrm{n}$ with increasing Pt composition in the bimetallic nanoparticles. The fact that the obtained $n$ values fall in between $\mathrm{n}=2$ and $=4$ likely suggests that both $2 \mathrm{e}^{-}$reduction to $\mathrm{H}_{2} \mathrm{O}_{2}$ and $4 \mathrm{e}^{-}$reduction to $\mathrm{H}_{2} \mathrm{O}$ processes are operative with the catalysts. Two possible origins include the presence of large-sized particles in the calcinated catalysts and the presence of possible surface segregation of the two metals on the bimetallic surface. A further delineation of the surface composition, particle size and calcination condition is in progress, which should provide more insights into the detailed catalytic mechanism.

\section{Conclusion}

In summary, the above electrochemical results have indicated that the bimetallic AuPt composition can significantly modify the electrocatalytic ORR properties of both $\mathrm{Au}$ and Pt. This finding has important implications to designing effective catalysts for improving fuel cell cathode reactions. The catalytic activity is highly dependent on the composition and calcination, which is by no means optimised at this stage and is in fact part of our on-going work aimed at the delineation of the activity correlation with composition, size, and calcination conditions. We believe that Au and AuPt nanoparticle catalysts are potentially viable candidates for fuel cell catalysts under a number of conditions. This conclusion is based on the characterization of $\mathrm{Au}$ and AuPt catalysts with different ratios and an initial comparison with commercial catalysts under the same voltammetric measurement conditions. The voltammetric data provide both qualitative and quantitative assessments of the potential viability, not the practical viability. A further comparison of our catalysts and commercial catalysts through testing in a commercial fuel cell is part of our ongoing studies, which will provide the basis for us to evaluate the practical viability in both qualitative and quantitative ways. In view of the fact that there is a miscibility gap over a wide composition range for bulk bimetallic AuPt metals (38), the understanding of how phase segregation is operative in the nanoscale AuPt under different temperatures and the ability to control it is another area of our research to manipulate the electrocatalytic ORR activities.

\section{Acknowledgements}

This work was supported in part by the G.R.O.W. of World Gold Council (RP03-03), the Petroleum Research Fund administered by the American Chemical Society (40253AC5M), National Science Foundation (CHM-0316322), and the $3 \mathrm{M}$ Corporation. M.M.M. thanks the Department of Defense for the National Defense Science \& Engineering Graduate Fellowship support sponsored by ARO.

\section{About the Authors:}

Mathew Maye is a Ph.D. candidate in the Department of Chemistry at State University of New York at Binghamton (SUNY). His research under the direction of Dr. Zhong focuses on the synthesis and processing of gold and alloy nanoparticles for fuel cells and novel nanoparticle assemblies. Nancy Kariuki is a Ph.D. candidate in the Department of Chemistry at SUNY. Her research under the direction of Dr. Zhong focuses on the design and fabrication of nanostructures for electroanalysis and electrocatalysis.

Dr. Jin Luo is a senior associate scientist working in Dr. Zhong's Laboratory at SUNY. His research interests include interfacial electrochemistry, catalysis, scanning probe microscopy, and nanoscale chemistry.

Dr. Li Han Her thesis research under the direction of Dr. Zhong focused on the characterization of nanostructured materials for chemical sensors. She is currently working at RTI International.

Peter Njoki is a Ph.D. candidate in the Department of Chemistry at SUNY. His thesis research under the direction of Dr. Zhong focuses on the synthesis of nanoparticles for catalysis.

Lingyan Wang is a Ph.D. candidate in the Department of Chemistry at SUNY. Her thesis research under the direction of Dr. Zhong focuses on synthesis and characterization of nanoparticles and assemblies for catalysis and sensors.

Yan Lin is a graduate student in the Department of Chemistry at SUNY. Her research under the direction of Dr. Zhong focuses on the characterization of nanoparticles for fuel cell catalysis.

Dr. H. Richard Naslund is a professor of the Department of Geological Sciences and Environmental Studies at SUNY. His research interests include Igneous petrology, experimental petrology, volcanology, and geochemistry.

Continued on p207 
12 J. Fischer-Bühner, Proceedings of Gold 2003: New industrial applications for gold, Vancouver, Canada, 28 September - 1 October 2003

13 G. Gafner, Gold Bull., 22(4), 1989, 112-122

14 T. Tani, K. Udoh, K. Yasuda, G. van Tendeloo and J. van Landuyt, J. of Dental Research, 70(10), 1991, 1350

15 K. Yasuda and M. Ohta, J. Less-Comm. Met., 70(2), 1980, 75

16 J. Fischer-Bühner, Proceedings of the Santa Fe Symposium on Jewelry Manufacturing Technology, 2001, 131

17 S.H. Avner, 1974. Introduction to Physical Metallurgy. 2nd ed., McGrawHill. pp. 132, 153
18 G. Normandeau, Proceedings of the Santa Fe Symposium on Jewelry Manufacturing Technology, 1996, 83

19 G. Normandeau and R. Roeterink, Gold Tech., 15, 1995, 4

20 M. Wolff and M.B. Cortie, Gold Bull., 1994, 27, 45

21 M. Cortie, I. Wolff, F. Levey, S. Taylor, R. Watt, R. Pretorius, T. Biggs and J. Hurly, Gold Technol., 1994, 4, 30

22 Japanese Patent 8013060: The Pilot Corp, 26 June 1994.

23 R.E Reed-Hill and R. Abbaschian, R. 1994. Physical Metallurgy Principles. 3rd ed., PWS Publishing. pp. 471, 470, 518

Continued from Maye et al p223

Dr. C.J. Zhong is an associate professor of Chemistry at SUNY. His research is in the interdisciplinary fields of analytical, materials, electrochemistry and nanotechnology. His recent work on nanoparticles and nanostructures is aimed at developing advanced materials and technologies for fuel cells, sensors and biosensors.

\section{References}

1 X.M. Ren, P. Zelenay, S. Thomas, J. Davey, S. Gottesfeld, J. Power Sources, 2000, 86, 111

2 D. Chu, R. Jiang, Solid State Ionics, 2002, 148, 591

3 U.A. Paulus, U. Endruschat, G.J. Feldmeyer, T.J. Schmidt, H. Bonnemann, R.J. Behm, J. Catal., 2000, 195, 383

4 E. Antolini, Mater. Chem. Phys., 2003, 78, 563

5 G.Q. Lu, A. Wieckowski, Curr. Opin. Coll. Interf. Sci., 2000, 5, 95

6 L. Xiong, A.M. Kannan, A. Manthiram, Electrochem. Commun., 2002, 4, 898

7 M. Haruta, Catal. Today, 1997, 36, 153

8 M. Haruta, M. Date, Appl. Catal. A, 2001, 222, 427

9 G.C. Bond, D.T. Thompson, Gold Bull., 2000, 33, 41

10 G.C. Bond, Gold Bull., 2001, 34, 117

11 C.W. Corti, R.J. Holliday, D.T. Thompson, Gold Bull., 2002, 35, 111

12 A. Ueda, M. Haruta, Gold Bull., 1999, 32, 3

13 D. Andreeva, Gold Bull., 2002, 35, 82

14 R. Grisel, K.J. Weststrate, A. Gluhoi, B.E. Nieuwenhuys, Gold Bull., 2002, 35,39

15 D.T. Thompson, Gold Bull., 1998, 31, 111 \& 1999, 32, 12

16 L.D. Burke, P.F. Nugent, Gold Bull., 1998, 31, 39

17 C.J. Zhong, M.M. Maye, Adv. Mater., 2001, 13, 1507

18 Gold 2003: New Industrial Applications for Gold, Proceeding Volume, World Gold Council, 2003

19 D. Cameron, R. Holliday, D. Thompson, J. Power Sources, 2003, 118, 298

20 Y. Lou, M.M. Maye, L. Han, J. Luo, C.J. Zhong, Chem. Commun., 2001, 473
21 J. Luo, M.M. Maye, Y. Lou, L. Han, M. Hepel, C.J. Zhong, Catal. Today, 2002, 77, 127

22 J. Luo, Y.B. Lou, M.M. Maye, C.J. Zhong, M. Hepel, Electrochem. Comm., 2001, 3, 172

23 J. Luo, V.W. Jones, M.M. Maye, L. Han, N.N. Kariuki, C.J. Zhong, J. Am. Chem. Soc., 2002, 124, 13988

24 M.M. Maye, J. Luo, Y. Lin, M.H. Engelhard, M. Hepel, C.J. Zhong, Langmuir, 2003, 19, 125

25 M.M. Maye, J. Luo, L. Han, N. Kariuki, C.J. Zhong, Gold Bull., 2003, 36, 75

26 C.J. Zhong, M.M. Maye, J. Luo, L. Han, N.N. Kariuki, in "Nanoparticles: Building Blocks for Nanotechnology", Ed. By V.M. Rotello, Kluwer Academic Publishers. Chapter 5, pp.113-144, 2004

27 C.J. Zhong, J. Luo, M.M. Maye, L. Han, N.N. Kariuki, in "Nanotechnology in Catalysis", Ed. By B. Zhou, S. Hermans, G.A. Somorjai, Kluwer Academic/Plenum Publishers. Vol. 1., Chapter 11, pp. 222-248, 2004

28 Y.D. Kim, M. Fischer, G. Gantefor, Chem. Phys. Lett., 2003, 377, 170

29 Y. Xu, M. Mavrikakis, J. Phys. Chem. B, 2003, 107, 9298

30 M.V. Brussel, G. Kokkinidis, I. Vandendael, C. Buess-Herman, Electrochem. Commun., 2002, 4, 808

31 M.S. El-Deab, T. Ohsaka, Electrochim. Acta, 2002, 47, 4255

32 M. Brust, M. Walker, D. Bethell, D.J. Schiffrin, R. Whyman, J. Chem. Soc., Chem. Commun. 1994, 801

33 M.M. Maye, W.X. Zheng, F.L. Leibowitz, N.K. Ly, C.J. Zhong, Langmuir, 2000, 16, 490

34 M.M. Maye, C.J. Zhong, J. Mater. Chem., 2000, 10, 1895

35 M.J. Hostetler, C.J. Zhong, B.K.H. Yen, J. Anderegg, S.M. Gross, N.D. Evans, M.D. Porter, R.W. Murray, J. Amer. Chem. Soc., 1998, 120, 9396

36 M.J. Hostetler, J.E. Wingate, C.J. Zhong, J.E. Harris, R.W. Vachet, M.R. Clark, J.D. Londono, S.J. Green, J.J. Stokes, G.D. Wignall, G.L. Glish, M.D. Porter, N.D. Evans, R.W. Murray, Langmuir, 1998, 14, 17

37 U.A. Paulus, A. Wokaun, G.G. Scherer, T.J. Schmidt, V. Stamenkovic, V. Radmilovic, N.M. Markovic, P.N. Ross, J. Phys. Chem. B, 2002, 106, 4181

38 "Catalysis by Metals and Alloys", Ed. By V. Ponec V and G.C. Bond, Elsevier, 1995 